\title{
COVID-19 should be considered an Adverse Childhood Experience (ACE)
}

\author{
Michelle A. McManus* and Emma Ball
}

Growing up with Adverse Childhood Experiences (ACEs) such as abuse, neglect, community violence, and homelessness, or growing up in a household where adults are experiencing mental health issues or harmful alcohol or drug use, has been shown to have long-lasting effects on people's lives. This is why the identification and prevention of ACEs and supporting children and adults affected has become a priority for government. Frontline organization practitioners are being encouraged to ask "what happened to you?" rather than "what is wrong with you?" (Centre for Health Care Strategies, 2016). The emphasis is on a personal experience and individual interpretation of an event(s). With COVID-19 being experienced so differently by different groups of people, we argue that the COVID-19 pandemic should be treated as an ACE, which could have short- and/or long-term impacts on a range of health and life outcomes. However, as with the existing dangers of ACE enquiry (Bateson, McManus, \& Johnson, 2019), we must remember it is not the ACE itself, but the perception and experience of the ACE which is key.

\section{What are ACEs?}

Adverse childhood experiences were first identified by Felitti et al. (1998), who explored the relationships between experiences of trauma in childhood and detrimental effects on health outcomes later on in life. There are 10 main categories of ACE: physical, emotional, and sexual abuse, physical and emotional neglect, parental abandonment, parental imprisonment, mental illness, domestic violence, and substance misuse (Public Health Scotland, 2020). Experiencing ACEs without supportive/protective factors to mitigate their effects, can impact on well-being and mental health and is often correlated with health-harming behaviours that can lead to long-term consequences such as increased risk of diabetes, heart disease, and cancer (Bellis et al., 2016). These non-communicable diseases reportedly kill 41 million people a year (World Health Organisation, 2018). Felitti also found a correlation between ACEs and poor educational outcomes, higher unemployment, and increased involvement with the criminal justice system. A recent report by Jones et al. (2020) found that violence costs the economic health system an estimated $£ 46.6$ million just in short-term consequences.
Adverse childhood experiences often co-occur (Hughes et al., 2017), with the two most common ACEs from the 21st century being those related to alcohol and substance misuse (Finkelhor, 2020), both of which have been exacerbated due to the COVID-19 pandemic and lockdown restrictions (Public Health England, 2020; Yougov Poll, 2020). While this paints a bleak picture, it is crucial to remember that ACEs are a risk factor and not a predetermined fate. Experiencing an ACE does not necessarily lead to poor outcomes. Adverse childhood experiences are not inevitable nor do they determine a child's future destiny (Burke, 2020). Furthermore, if we understand the potential impact of an ACE we can take action. By considering COVID-19 as an ACE in its own right, we hope to raise awareness of potentially harmful effects, both short- and long-term, as a result of the COVID-19 pandemic and its restrictive measures. Moreover, we advocate that, as with all experiences of childhood adversity, this calls for understanding the individual and personal experience and responding with a trauma-informed approach to support children and families.

\section{International impact of ACEs}

Research has been carried out throughout the world, providing a variety of statistics on ACEs. It has been reported that, within North America, ACEs cost the economy US\$748 million (America's Health Rankings, 2020). Across the globe, Kezelman et al. (2015) estimate the cost of unresolved childhood trauma in Australia at AU\$9.1 billion. The World Health Organisation (2019) notes that ACEs cost North America and Europe US $\$ 1.3$ trillion dollars a year. In response to this, money is being invested in support for those who have experienced ACEs. Kaiser Permanente, a network of health care providers in the United States and founder of the ground-breaking 1998 ACE study, has recently invested $£ 2.75$ million in research in the prevention and reduction of ACEs (Kaiser Permanente, 2019). The ACEs movement has been expanding massively, evidenced by the worldwide network ACEs Connection, which has over 40,000 members and advocates for trauma-informed resources based on a growing body of science.

Within the United Kingdom, all countries have shown a commitment to tackling ACEs (Public Health Scotland,

Correspondence to: Dr. M. A. McManus, Head of Criminal Justice, School of Justice Studies, Liverpool John Moores University, Liverpool, UK.
E-mail: m.a.mcmanus@limu.ac.uk
To cite: McManus, M. A., \& Ball, E. (2020). COVID-19 should be considered an Adverse Childhood Experience (ACE). Journal of Community Safety and Well-Being,
5(4), 164-167. https://doi.org/10.35502/icswb.166
@ Author(s) 2020. Open Access. This work is distributed under the Creative Commons BY-NC-ND license. For commercial re-use, please contact sales@sgpublishing.ca. gPUBLISHING Published by SG Publishing Inc. CSRA Official publication of the Community Safety Knowledge Alliance. 
2020; Department for Health and Social Care, 2018; Bellis et al., 2016; Safeguarding Board for Northern Ireland, 2018), and the ACE movement is continuing to evolve. There are various tools used to capture the prevalence of ACEs, such as The World Health Organisation's international questionnaire (n.d.), resulting in ACE scores. Whilst it is positive to recognize potential trauma a person has experienced, it is important to remember that the narrative must go deeper and that experience is not accurately reflected simply in a score (Hambrick et al., 2019).

\section{How can COVID-19 be an ACE when the whole world has experienced it?}

Our whole argument since working on the adoption of ACEs within the criminal justice system (see Early Action Together, 2018) has been warning about the simplification of the model that allows practitioners to use ACEs as a checklist. In our paper discussing the misuse of ACEs (Bateson et al., 2019), we warned about organizations that were either refusing or including an individual for treatment, intervention, or service based on the number of ACEs they checked. However, like COVID-19, it is not the presence of the ACE but the personal experience we need to focus on.

We have all experienced the effects of the COVID-19 pandemic one way or another. Lots of families have talked about the great positives of COVID-19 in theirs and their children's lives, such as spending more time together and "strengthening family bonds" (Clayton \& Potter, 2020). A recent article also highlighted additional positives, such as embracing a much more dynamic and less routine-based lifestyle with our families (Pope, 2020). Then there are those families that have had to balance full-time jobs with children at home (Craig \& Churchill, 2020). Some parents have stated that they have seen changes in their children's behaviour, agreeing that this has worsened in lockdown (University of Oxford, 2020). The knock-on effect of this can be increased screen time due to isolation at home, with parents at home working and providing reduced levels of supervision of their children's online activities and engagement. The World Health Organisation (2020) has warned this could lead to increases in sedentary lifestyle, changes in mood and behaviour, and, of course, the risk of being exposed to harmful content, exploitation, and cyberbullying.

The impact of lockdown is diverse, but while most people will recover from the challenges posed by the COVID-19 pandemic, the assumption cannot be made that all children will simply "bounce back."

The danger surrounding COVID-19 is that we may consider that everyone has been adversely affected by COVID-19 and that, therefore, any changes in behaviour, mood, physical appearance, emotions, an so on are just a natural consequence of COVID-19 and the social restrictions that we all had to abide by. Thinking this way is simply wrong. It assumes that there was an equal playing field prior to COVID-19 and ignores the protective factors, often taken for granted, in place for some children (Madigan et al., 2018). These include stable attachments (Stacy, 2006) and strong relationships (Bright, 2017) with loving extended family or friends, as well as permanent and secure accommodation. It also implies a life free from the horrors of hunger, domestic abuse, parental long-term unemployment, mental illness, and substance misuse. If these protective factors were absent before, there is a strong possibility that the situation is deteriorating rapidly, as evidenced by the Office of National Statistics (2020) reporting increased unemployment, increased risky alcohol consumption (Public Health England, 2020), and increased referrals for urgent mental health cases (Royal College of Psychiatrists, 2020). In addition to this are the national spikes in domestic abuse cases: the Telegraph newspaper reported an increase of 54\% in women needing emergency accommodation in July alone and an $800 \%$ increase in calls to Refuge's National Domestic Abuse Helpline (Davies, 2020). Are we expecting children from these chaotic households to have experienced the same ups and downs of lockdown as those who have regular and sustained protective/supportive factors? And let's remember, the restrictions are far from over.

What are the benefits of including COVID-19 as an ACE? It is well known that many organizations have now bought into the concept of trauma-informed practice. The College of Policing (2018), England's National Health Service (2019), Trauma Informed Schools UK (2020), and Criminal Justice agencies (Papamichael, 2019) have all come to the conclusion that considering ACEs is an essential component when dealing with people, often vulnerable, on a daily basis. These organizations are spending thousands on traumainformed training and are no doubt already talking about COVID-19, but are they considering this as a traumatic, individualized experience?

\section{CONCLUSION}

Our point has always been that the simplification of ACEs could be the potential downfall of the concept. The frequency, severity, chronicity, and type of ACE, along with such factors as the age of the child and other socio-demographic factors, will vary the impact of each ACE experience (Bateson et al., 2019). It is likely that, upon returning to schools, teachers will have witnessed changes in the behaviour of children who have experienced trauma as a result of the lockdown. Welcome guidance has already begun to be circulated by Merseyside Violence Reduction Partnership (2020) and Lancashire Violence Reduction Unit (2020) to assist schools in recognizing the potential signs of trauma.

Adverse childhood experiences can affect people either directly or indirectly. The same is true for COVID-19. In a world where we look to be informed by evidence and are "guided by science," the ACE-awareness movement needs to become mainstream and consider a variety of adverse experiences, such as the COVID-19 pandemic. If individuals are aware of the impact of ACEs and their relevance to COVID-19, they are more likely to be empowered to make decisions for themselves and their families. The pandemic has impacted upon all children, but not all children will have experienced COVID-19 as an ACE.

Adopting COVID-19 into the ACEs framework will encourage practitioners to ask the question "how was lockdown for you?" Simply pausing to consider the varied impact of COVID-19 and basing next steps in decision-making on their experience, not on our assumptions of their experience, can be the difference between making people safe and allowing them to continue to be harmed. 


\section{CONFLICT OF INTEREST DISCLOSURES}

The authors declare that there are no conflicts of interest.

\section{AUTHOR AFFILIATIONS}

* Dept. of Criminal Justice, School of Justice Studies, Liverpool John Moores University, United Kingdom.

\section{REFERENCES}

America's Health Rankings. (2020). Retrieved from: https://www. americashealthrankings.org/explore/health-of-women-and-children/ measure/ACEs/state/U.S

Bateson, K., McManus, M., \& Johnson, G. (2019). Understanding the use, and misuse, of adverse childhood experiences (ACEs) in traumainformed policing. The Police Journal, 93(2), 131-145.

Bellis, M. A., Ashton, K., Hughes, K., Ford, K., Bishop, J., \& Paranjothy, S. (2016). Adverse childhood experiences (ACEs) in Wales and their impact on health in the adult population: Mariana Dyakova. European Journal of Public Health, 26(1 Suppl 1). doi:10.1093/ eurpub/ckwl67.009.

Burke, N. (2020). Adverse childhood experiences. Retrieved from: https://burkefoundation.org/what-drives-us/adverse-childhoodexperiences-aces/

Bright, M. (2017). Why stable relationships are "poison control" in fighting trauma and stress in kids. The Conversation. Retrieved from: https:// theconversation.com/why-stable-relationships-are-poison-control-infighting-trauma-and-stress-in-kids-77387

Clayton, C., \& Potter, M. (2020) British families in lockdown. Leeds Trinity University. Retrieved from: https://www.leedstrinity.ac.uk/news/ archive/2020/covid-19-study-reveals-positive-impact-of-lockdownon-family-dynamics-and-wellbeing.php

College of Policing. (2018). Responding to trauma in policing. Retrieved from: https://www.college.police.uk/What-we-do/Support/Healthsafety/Documents/Responding-to-trauma-in-policing.pdf

Craig, L., \& Churchill, B. (2020). Dual-earner parent couples' work and care during COVID-19. Gender, Work \& Organization. Retrieved from: doi:10.1111/gwao.12497

Davies, G. (2020, July 23). Domestic violence helpline calls up by $80 \%$ in June amid warnings that surge will continue in autumn. The Telegraph Newspaper. Retrieved from: https://www.telegraph.co.uk/ news/2020/07/23/domestic-violence-helpline-calls-80-june-amidwarnings-surge/

Department for Health and Social Care. (2018). Routine enquiry about adverse childhood experiences: implementation pack pilot evaluation, final report. Retrieved from: https://www.gov.uk/government/ publications/routine-enquiry-about-adverse-childhood-experiencesimplementation-pack-evaluation

Early Action Together. (2018). Royal Society for Public Health. Retrieved from: https://www.rsph.org.uk/our-work/resources/early-actiontogether-learning-network.html

Felitti, V. J., Anda, R. F., Nordenberg, D., Williamson, D. F., Spitz, A. M., Edwards, V., ... Marks, J. S. (1998). Relationship of childhood abuse and household dysfunction to many of the leading causes of death in adults: The adverse childhood experiences (ACE) study. American Journal of Preventive Medicine, 14(4), 245-258.

Finkelhor, D. (2020). Trends in adverse childhood experiences (ACEs) in the United States. Child Abuse \& Neglect, 108, 104641

Hambrick, E., Brawner, T. W., Perry, B. W., Brandt, K., Hofmeister, C., \& Collins, J. O. (2019). Beyond the ACE score: Examining relationships between timing of developmental adversity, relational health and developmental outcomes in children. Archives of Psychiatric Nursing, 33(3), 238-247.

Hughes, K., Bellis, M. A., Hardcastle, K. A., Sethi, D., Butchart, A., Mikton, C., ... \& Dunne, M. P. (2017). The effect of multiple adverse childhood experiences on health: a systematic review and metaanalysis. The Lancet Public Health, 2(8), 356-366.

Jones, L., Bigland, C., \& Quigg, Z. (2020). Costs of violence to the Welsh health care system. Public Health Institute, Liverpool John Moores University. Retrieved from: https://www.violencepreventionwales. co.uk/cms-assets/research/Costs-of-violence-to-the-healthcaresystem-in-Wales.pdf

Kaiser Permanente. (2019). Funding new research to prevent childhood trauma. Retrieved from: https://about.kaiserpermanente.org/community-health/news/funding-new-research-to-prevent-childhood-trauma

Kezelman, C., Hossack, N., Stavropoulos, P., \& Burley, P. (2015). The cost of unresolved childhood trauma and abuse in adults in Australia: A report for adults surviving child abuse. Retrieved from: https://www.qldfamilylawnet.org.au/sites/qldfamilylawnet/files/ gflpn/The\%20cost\%20of\%20unresolved\%20trauma_budget\%20 report\%20fnl.pdf

Lancashire Violence Reduction Unit. (2020). Post COVID-19 traumainformed guidance for schools. Retrieved from: http://www. lancashiresafeguarding.org.uk/media/19155/LVRN-Post-COVID19-Trauma-Informed-Guidance-for-Schools-FINAL.pdf

Madigan, S., Racine, N., \& Tough, S. (2018). How compassion can triumph over toxic childhood trauma. The Conversation. Retrieved from: https://theconversation.com/how-compassion-can-triumphover-toxic-childhood-trauma-90756

Menschner, C., \& Maul, A. (2016). Key ingredients for successful traumainformed care implementation. Centre for Health Care Strategies. Retrieved from: http://www.chcs.org/media/Brief-Key-Ingredientsfor-TIC-Implementation-1.pdf

Merseyside Violence Reduction Partnership. (2020). Additional guidance when considering permanent exclusion. Retrieved from: https:// merseysidevrp.com/media/1200/mvrp-extra-guidance-for-headteachers-re-permanent-exclusion-sept-2020.pdf

National Health Service. (2019). Providing effective trauma informed care for women. Retrieved from: https://www.england.nhs.uk/Itphimenu/ mental-health/providing-effective-trauma-informed-care-for-women/

Office of National Statistics. (2020, September). Labour market overview, UK. Retrieved from: https://www.ons.gov.uk/employmentandlabourmarket/peopleinwork/employmentandemployeetypes/bulletins/ uklabourmarket/september2020

Papamichael, D. (2019, July 22). Can trauma-informed practice transform the criminal justice system? Rocket Science. Retrieved from: http:// rocketsciencelab.co.uk/2019/07/22/can-trauma-informed-practicetransform-the-criminal-justice-system/

Pope, D. (2020). Routine: Less is often more when it comes to children's development. The Conversation. Retrieved from: https://theconversation.com/routine-less-is-often-more-when-it-comes-to-childrensdevelopment-145900

Public Health England. (2020). Wider impacts of COVID-19 on health (WICH) monitoring tool. Retrieved from: https://analytics.phe.gov. uk/apps/covid-19-indirect-effects/

Public Health Scotland. (2020). Adverse childhood experiences (ACEs). Retrieved from: http://www.healthscotland.scot/population-groups/ children/adverse-childhood-experiences-aces/overview-of-aces

Royal College of Psychiatrists. (2020). Psychiatrists see alarming rise in patients needing urgent and emergency care and forecast a "tsunami" of mental illness. Retrieved from: https://www.rcpsych.ac.uk/ news-and-features/latest-news/detail/2020/05/15/psychiatristssee-alarming-rise-in-patients-needing-urgent-and-emergency-care

Safeguarding Board for Northern Ireland. (2018). Evidence review - developing trauma-informed practice in Northern Ireland. Retrieved from: https://pureadmin.qub.ac.uk/ws/portalfiles/portal/168311525/ ACEs_Report_A4_Feb_2019_Developing_a_Trauma_Informed_ Approach_Full_Evidence_Review.pdf 
Stacy, P. D. (2006). Early childhood attachments as a protective factor. Journal of Evidence-Based Social Work, 3(2), 49-65.

Trauma Informed Schools UK. (2020). Retrieved from: https://www. traumainformedschools.co.uk

University of Oxford. (2020). Children show increase in mental health difficulties over COVID-19 lockdown. Retrieved from: https://www. ox.ac.uk/news/2020-06-16-children-show-increase-mental-healthdifficulties-over-covid-19-lockdown

World Health Organisation. (2018). Noncommunicable diseases factsheet. Retrieved from: https://www.who.int/news-room/fact-sheets/ detail/noncommunicable-diseases

World Health Organisation. (2020). Excessive screen use and gaming considerations during \#COVID19. Retrieved from: http://www.emro. who.int/mnh/news/considerations-for-young-people-on-excessivescreen-use-during-covid19.html
World Health Organisation. (n.d.). Adverse childhood experiences international questionnaire (ACE-IQ). Guidance for analysing ACE-IQ. Retrieved from: https://www.who.int/violence_injury_prevention/ violence/activities/adverse_childhood_experiences/guidance_for_ analysing.pdf? $u a=1$

World Health Organisation. (2019). Preventable trauma in childhood costs North America and Europe US\$1.3 trillion a year. Retrieved from: https://www.euro.who.int/en/health-topics/ noncommunicable-diseases/mental-health/news/news/2019/9/ preventable-trauma-in-childhood-costs-north-america-and-europeus\$-1.3-trillion-a-year

Yougov. (2020). How are British drinking habits shifting under lockdown? Retrieved from: https://yougov.co.uk/topics/food/ articles-reports/2020/04/08/how-are-british-drinking-habitsshifting-under-loc 